\title{
The impact of tobacco control policies in Albania
}

\author{
Eduard Zaloshnja, ${ }^{1}$ Hana Ross, ${ }^{2}$ David T Levy ${ }^{3}$
}

${ }^{1}$ Pacific Institute for Research and Evaluation, Beltsville, Maryland, USA

${ }^{2}$ International Tobacco Surveillance, American Cancer Society, Atlanta, Georgia, USA ${ }^{3}$ Pacific Institute for Research and Evaluation, University of Baltimore, Baltimore, Maryland, USA

\section{Correspondence to} Dr Eduard Zaloshnja, Pacific Institute for Research and Evaluation, 11720 Beltsville Dr Suite 900, Beltsville, MD 20705 , USA; zaloshnja@pire.org

Received 2 November 2009 Accepted 7 May 2010

Published Online First

2 August 2010

\section{(2) UNLOCK:}

This paper is freely available online under the BMJ Journals unlocked scheme, see http:// tobaccocontrol.bmi.com/site/ about/unlocked.xhtml

\section{ABSTRACT}

Objective To assess the impact of a tobacco control law adopted in Albania in 2007 and to estimate the share of illicit cigarettes on the market.

Design Comparative analysis of two waves of a nationally representative household survey, one conducted before the new law went into effect and the other after 2 years. Official sales data were contrasted with the consumption estimate based on the survey.

Main outcome measures Smoking prevalence, quit attempts, exposure to cigarette advertising, exposure to second-hand smoke, total cigarette consumption, share of illicit packs among packs possessed by smokers.

Results Despite the adoption of strong smoke-free policies and adverting restrictions, smoking prevalence in Albania has risen. The increase in prevalence has been driven by higher smoking rates among females $118.9 \%$ in 2007 vs $29.3 \%$ in 2009$)$ and young adults $(23.2 \%$ in 2007 vs $38.5 \%$ in 2009 among $18-19$ year olds). Selfreported exposure to second-hand smoke and cigarette advertising have been reduced since 2007. The majority of respondents are still exposed to second-hand smoke and more than half are exposed to tobacco advertising. Nevertheless, there are signs that the consumption of illicit cigarettes is declining.

Conclusions The impacts of smoke-free policies and an advertising ban have been limited due to lack of enforcement and failure to adopt a comprehensive set of tobacco control measures. These measures should include sizeable and regular tobacco tax increases in excess of the general level of inflation and income growth. The decline in the share of illicit cigarettes should improve the effectiveness of the cigarette tax policy.

\section{INTRODUCTION}

Until 1990, all cigarettes sold in Albania were produced by a state monopoly and were of poor quality. With economic liberalisation and the freedom to travel after the fall of communism, Albanians' exposure to the outside world dramatically increased the demand for Western-type products including cigarettes. Foreign products symbolised prestige and a promise of future economic prosperity. Cigarette smoking among women, considered socially unacceptable during the communist regime, became a sign of emancipation and a modern lifestyle, especially among the younger generations. The fall of communism created a favourable climate for foreign investment and trade, which led to higher incomes, which encourage higher consumption.

International tobacco companies seized the opportunity to profit from the increased purchasing power and limited tobacco control policies, and flooded the market with foreign cigarettes. At the same time cigarettes became heavily advertised while taxes collected on them remained low. During the 1990s, domestic cigarette production was privatised, but could not compete with foreign imports. ${ }^{1}$ For example, between August 2008 and July 2009, domestic production was only 200 metric tons (conversation between Vice Minister of Finance Mima Florion and H Ross, Tirana, 2009), while imports clearing customs reached 4037 metric tons. ${ }^{2}$ However, not all cigarettes were legally imported. In 2001, the tobacco industry estimated that illicit cigarettes occupied about $72 \%$ of the total market. ${ }^{3}$ The WHO reported that between $40 \%$ and $50 \%$ of cigarettes consumed in Albania were illicit in $2007 .{ }^{4}$

In response to alarming trends in smoking prevalence, ${ }^{5}$ the Albanian government began to embrace tobacco control policies. In 2000 it adopted a set of 'National Tobacco Control Provisions' which consisted of a ban on tobacco advertising on television, radio, the printed media and billboards; public information campaigns on the dangers of tobacco use; health warnings and the disclosure of tobacco product ingredients; and restrictions on smoking in public places such as educational and healthcare facilities, government buildings and public transport. The government signed in 2004 and ratified in 2006 the Framework Convention for Tobacco Control (FCTC). However, advertising on billboards and at the point of sale and other promotional activities were still allowed. In 2006, Albania increased cigarette taxes, and in May 2007 banned all outdoor tobacco advertisements including billboards, prohibited smoking in all public places including restaurant and bars, and banned sales of tobacco products to those under 18 years of age. At that time, the smoke-free regulations were among the strongest in Europe.

In order to assess the impact of the 2007 policies, the American Cancer Society funded two waves of a population-level survey. The first survey, the Albanian Adult Tobacco Survey (AATS-1), was conducted in April 2007, prior to the implementation of the May 2007 law, and established a baseline for measuring its impact. The second survey (AATS-2) was conducted 2 years later, in April 2009

This paper evaluates the impact of the policy change on smoking behaviour, exposure to tobacco advertising and second-hand smoke. It also assesses the trend in cigarette illicit trade based on additional questions included in the AATS-2, which were not included in AATS-1.

\section{DATA AND METHODS}

\section{Sample}

Both waves of the AATS survey collected data from a representative sample of 4000 adults (age 18 years and older) living in private households in Albania. For the AATS-1, the population was stratified into 
urban and rural areas. Within these two strata, the sample was selected through a two-stage process. In the first stage, the population of each stratum was divided into 36 districts and each district was subdivided into 400-inhabitant segments, or primary sampling units (PSUs). There were a total of 7823 PSUs, of which 3518 were from urban areas. These PSUs were sorted by strata and district using systematic sampling, and 500 PSUs were chosen, 250 of which were in urban areas. In the second stage, eight households were randomly selected for each PSU. All household members 18 years and over present at the time of the visit were eligible to participate and each respondent individually answered the questions. The minimum response rate to the face-to-face interviews in AATS- 1 was $82.3 \%$. The minimum response rate, as defined by the American Association for Public Opinion Research, ${ }^{6}$ was calculated as the number of complete interviews divided by the number of interviews (complete plus partial) plus the number of non-interviews (refusal and break-off plus non-contacts plus others) plus all cases of unknown eligibility (unknown if housing unit, plus unknown, other).

For the AATS-2, the interviewers attempted to contact the same households which participated in the AATS-1. They were able to re-interview $80.8 \%$ of AATS-1 participants. Using the sampling design developed for the AATS-1, some members of the AATS-1 households were newly included in AATS-2 since they had become adults and some new households were also included to reach the 4000 quota. The response rate for the new participants was $80.5 \%$. We used a two-sided $z$ test for each demographic group in AATS-1 and AATS-2 samples to test for differences in their demographic composition. All $p$ values were $<0.01$. As table 1 indicates, both samples represent the Albanian adult population well, with the exception of a significant oversampling of males and females in the 45-54-year-old age group and a significant under-sampling of females over 65 years of age. This was corrected by applying the weighing techniques developed for the AATS- 1.5

\section{Data collection instruments}

The questionnaire used in both surveys was based on a shorter version of the Global Adult Tobacco Survey prototype 5 and collected data on smoking prevalence, cessation, exposure to second-hand smoke, and socio-economic variables relevant to smoking behaviour. ${ }^{5}$ The AATS-1 and the AATS-2 questionnaires were similar, although AATS-2 included additional questions on illicit cigarettes.

In the prevalence section of the survey, individuals were first asked if they were current smokers (daily or occasional). Occasional smokers reported how many days per week they typically smoked. All smokers provided the number of cigarettes they smoked during a typical day (smoking intensity), while nonsmokers were asked if they were former smokers.

Current smokers reported if they had made an attempt to quit in the last year, and if they had been advised by a doctor to quit smoking. Former smokers estimated how long they had abstained from cigarette smoking. All survey participants were asked about their exposure to second-hand smoke and tobacco advertising (see tables 2 and 3 for details on the questions).

Preferred cigarettes brands, cigarette prices and place of purchase were reported by current smokers. Cigarette pack characteristics related to the presence of tax stamps and warning labels in the Albanian language were either recorded by the AATS-2 interviewers based on an inspection of the cigarette pack, or were provided by smokers when they refused to show their packs. The AATS-2 respondents were also asked whether they (knowingly) purchased illicit cigarettes during the last
Table 1 Sample and population demographics

\begin{tabular}{lrrr}
\hline & $\begin{array}{l}\text { 2007 Sample } \\
\text { distribution (\%) }\end{array}$ & $\begin{array}{l}\text { 2009 Sample } \\
\text { distribution (\%) }\end{array}$ & $\begin{array}{l}\text { 2007 Population* } \\
\text { distribution (\%) }\end{array}$ \\
\hline Males & & & \\
18-19 years & 2.75 & 2.70 & 2.94 \\
20-24 years & 5.95 & 5.60 & 6.73 \\
25-34 years & 8.85 & 9.20 & 9.68 \\
35-44 years & 10.33 & 10.47 & 9.26 \\
45-54 years & 13.88 & 13.90 & 8.93 \\
55-64 years & 8.85 & 8.70 & 5.84 \\
Over 65 years & 4.00 & 4.18 & 6.07 \\
Total males & 54.61 & 54.75 & 49.45 \\
Females & & & \\
18-19 years & 2.25 & 2.28 & 2.77 \\
20-24 years & 5.25 & 5.50 & 6.73 \\
25-34 years & 8.53 & 8.70 & 10.41 \\
35-44 years & 10.60 & 10.48 & 9.66 \\
45-54 years & 11.65 & 11.27 & 8.59 \\
55-64 years & 4.78 & 4.82 & 5.56 \\
Over 65 years & 2.35 & 2.20 & 6.84 \\
Total females & 45.41 & 45.25 & 50.55 \\
\hline
\end{tabular}

*Source: the Albanian Statistics Institute's web page: http://www.instat.gov.al/graphics/ doc/tabelat/Treguesit\%20Sociale/Popullsia/P0P\%202008/pop4.xls.

12 months. It is not illegal to purchase illicit cigarettes in Albania and smokers would not be subject to legal sanction by providing this information. Selling illicit cigarettes carries a fine of approximately US\$500, but the law is not enforced.

\section{Statistical analysis}

To estimate the impact of tobacco control policies, prevalence estimates were compared between the two waves of the survey. Individual McNemar change tests were applied to test for changes in prevalence by demographic group. $T$ tests were used to test if the average number of cigarettes smoked had significantly changed from 2007 to 2009. Because the demographic profiles of the two surveys were very similar, we used full samples of 4000 respondents in calculating prevalence estimates for each demographic group. To be representative of the adult population and to account for sample design/weighting in the estimation procedures, all statistical analyses were conducted with weighted data using linearisation methods in STATA 9.2.

\section{RESULTS}

\section{Smoking prevalence}

Smoking prevalence, broken down by age, sex and smoking frequency, is reported in table 4 for both surveys. Male smoking prevalence remained relatively constant; the changes for both daily and occasional smokers were not statistically significant $(p=0.23$ and $p=0.42$, respectively). However, female smoking prevalence increased significantly from $18.9 \%$ to $29.3 \%(p=0.01)$, with relatively proportional increases in daily and occasional smokers.

The increase was most marked among 18-19year olds, especially daily male smokers (from $26.9 \%$ to $44.4 \%$; $p=0.001$ ) and occasional female smokers $(2.9 \%$ to $16.1 \%$; $=0.001)$. A comparison of the data from the two surveys reveals that both of these increases were particularly pronounced in rural areas (from $16.4 \%$ to $50.9 \%$ among young male daily smokers and from $0.2 \%$ to $12.8 \%$ for occasional female smokers, respectively $(\mathrm{p}<0.001)$; data not shown but available upon request).

\section{Smoking intensity}

Smoking intensity for daily smokers was 21 cigarettes per day. This statistic did not change between the two surveys and 
Table 2 Exposure to second-hand smoke, 2007 and 2009

\begin{tabular}{lcc}
\hline & $\mathbf{2 0 0 7}$ & $\mathbf{2 0 0 9}$ \\
\cline { 2 - 3 } \% Of adults exposed & \\
\hline Did anybody smoke in these indoor places you visited & during the past 7 days? & \\
Government offices & 59 & $26^{*}$ \\
Medical facilities & 35 & $8^{*}$ \\
Schools/universities & 38 & $20^{*}$ \\
Private businesses & 83 & $64^{*}$ \\
Cafes/bars/night clubs & 100 & $84^{*}$ \\
Restaurants & 86 & $66^{*}$ \\
Are there members of the household (including you) who smoke regularly in the home? & 27 & $37^{*}$ \\
No, not in any places & 48 & $33^{*}$ \\
Yes, in all places & 25 & 30 \\
Yes, in some places & & \\
If you mostly work indoors, which of the following best describes the smoking policy \\
where you work: & 62 & $37^{*}$ \\
No rules & 18 & $27^{*}$ \\
Smoking is allowed in some areas & 20 & $37^{*}$ \\
Smoking is not allowed & 25 & $42^{*}$ \\
During the past 7 days, did anyone smoke in indoor areas where you work? & $58^{*}$ \\
No & 75 & \\
Yes & &
\end{tabular}

Sample size was 4000 . All estimates are weighted.

*Difference from the year 2007 is statistically significant at the $95 \%$ confidence level.

neither did the fact that male smokers consume more cigarettes than female smokers ( 23.5 vs 12.5 cigarettes per day; $\mathrm{p}=0.001$ ). Smoking intensity for occasional smokers decreased from 16.7 to 14.1 cigarettes per week $(p=0.03)$ between 2007 and 2009 while maintaining the gender gap (19.2 vs 12.1 cigarettes per week among males and females, respectively; $\mathrm{p}=0.002$ ).

\section{Quitting behaviours}

Table 4 indicates that between the two surveys, there was no significant change in the prevalence of former smokers $(11.9 \%$ vs $10.7 \%$ for males, $p=0.18$; $3.3 \%$ vs $2.9 \%$ for females, $p=0.21$ ). Also, the quit ratio, defined as the ratio of former smokers to ever smokers, did not change significantly ( $15.4 \%$ vs $14.2 \%$ for males, $\mathrm{p}=0.27 ; 10.1 \%$ vs $13.3 \%$ for females, $\mathrm{p}=0.06$ ). The quit ratio among 18-24 years olds, although very low, increased from 2007 to 2009 for both genders ( $p=0.04$ for males and $p=0.01$ for females).

As table 5 shows, during the year preceding the 2009 survey, $30.3 \%$ of daily smokers stopped smoking for at least $24 \mathrm{~h}$ in an attempt to quit smoking, as opposed to $26.6 \%$ in 2007 ( $p=0.07$ ). This increase, however, was statistically significant for females (34.6\% in 2009 vs $26.2 \%$ in 2007; $p=0.02)$, and males aged $25-34$ years $(31.6 \%$ in 2009 vs $23.1 \%$ in 2007 ; $\mathrm{p}=0.01)$.

Table 3 Exposure to cigarette advertisements

\begin{tabular}{|c|c|c|c|c|c|c|}
\hline & \multicolumn{6}{|c|}{ Percent of adult population } \\
\hline & \multicolumn{3}{|c|}{2007} & \multicolumn{3}{|l|}{2009} \\
\hline & All & Urban & Rural & All & Urban & Rural \\
\hline \multicolumn{7}{|l|}{$\begin{array}{l}\text { In the last } 1 \text { month, have you seen/ } \\
\text { noticed any advertisements promoting } \\
\text { cigarettes or tobacco products in the } \\
\text { following: }\end{array}$} \\
\hline Outdoors & 75.0 & 85.6 & 66.6 & $51.5^{*}$ & $45.8^{*}$ & $56^{*}$ \\
\hline Electronic media & 21.7 & 24.6 & 19.4 & 20.5 & $15.7^{*}$ & 24.3 \\
\hline Stores where cigarettes are sold & 47.2 & 48.6 & 46.1 & $21.5^{*}$ & $22.9^{*}$ & $20.5^{*}$ \\
\hline Newspapers/magazines & 16.6 & 21.3 & 13.0 & $7.9^{*}$ & $7.3^{*}$ & 8.3 \\
\hline Movie theatres & 0.5 & 1.0 & 0.1 & $2.1^{*}$ & 2.6 & $1.8^{*}$ \\
\hline Internet & 1.9 & 3.6 & 0.6 & $4.0^{*}$ & 5.5 & $2.8^{*}$ \\
\hline
\end{tabular}

Sample size was 4000 . All estimates are weighted.

*Difference from the year 2007 is statistically significant at the $95 \%$ confidence level.
Only $37.3 \%$ of smokers who saw a doctor during the year preceding the second survey received advice from their healthcare providers to quit smoking. The decline from 2007 (48.3\% advised) was statistically significant $(p=0.02)$. However, the percentage of smokers who saw a doctor increased from $45.8 \%$ to $58.9 \%$ between 2007 and $2009(p=0.01)$.

\section{Exposure to second-hand smoke}

Self-reported exposure to second-hand smoke at home, work and in public places (see table 2) decreased significantly since smokefree legislation was enacted in 2007. The largest impact was recorded in medical facilities, where the self-reported exposure declined from $35 \%$ to $8 \%$ of respondents $(p=0.001)$. The second and the third largest decline in exposure occurred in government offices (from $59 \%$ to $26 \% ; \mathrm{p}=0.01$ ) and in educational institutions (from 38\% to 20\%; $p=0.02$ ). Exposure to second-hand smoke remained high in private workplaces, restaurants and cafes/bars/night clubs (64\%, $66 \%$ and $84 \%$, respectively).

\section{Exposure to advertising}

Self-reported exposure to cigarette advertising declined significantly between 2007 and 2009 (table 3). About half (52\%) of the respondents reported exposure to outdoor cigarette advertising (on posters, billboards, or public transportation vehicles) in the month preceding participation in AATS-2 compared to $75 \%$ in AATS- $1(p=0.001)$. This decline was more dramatic in urban areas (from $85.6 \%$ to $45.8 \% ; \mathrm{p}<0.001$ ). Participants reported less advertising exposure in stores and print media between 2007 and 2009 (for both, $p=0.002$ ). A significant decrease in electronic media exposure was seen only in urban areas $(p=0.02)$. Few have been exposed to cigarette advertising on the internet or in movie theatres, but an increase was observed in each of these media.

\section{Cigarette brands and their prices}

The Albanian cigarette market is dominated by imports from Greece, Italy and Turkey. The most popular of the 138 different brands recorded as the most recent purchase during the 2009 survey was Karelia Slims (29\% of all smokers, but 36\% of female smokers). The second and third most popular brands were Winston Blue (9\%) and Slims (9\%). These brands are advertised as 'light' cigarettes, but the data did not distinguish whether these choices are motivated by tastes, concerns about the health impact of tobacco use, or by tobacco advertising and marketing.

Using the self-reported cigarette prices and brands, the weighted average price for a pack of 20 cigarettes at the time of the second survey was 137 Lek (US\$1.40). More than half of all smokers purchased cigarettes at a price of 130 Lek, and $88.8 \%$ purchased at a price of between 100 and 150 Lek. Cigarettes cheaper than 100 Lek were purchased by only $0.5 \%$ of smokers, and cigarettes costing more than 150 Lek were purchased by $10.7 \%$ of smokers. Interestingly, prices of cigarettes without tax stamps (suspected of being illicit) were on average 29\% higher than prices of regular cigarettes. The average price of a cigarette pack increased by $9.6 \%$ between the AATS- 1 and AATS-2. Since the Consumer Price Index increased by 6.2\% between April 2007 and April 2009, ${ }^{8}$ the inflation-adjusted average cigarette price increased by $3.4 \%$. The inflation-adjusted price of the most popular brand, Karelia Slims, increased by $4.8 \%$. No change in cigarette specific taxes occurred between surveys.

\section{Illicit cigarettes}

In 2009 , approximately $19 \%$ of smokers in urban areas and $27 \%$ in rural areas suspected that some of the cigarettes that they had 
Table 4 Smoking prevalence (in \%) among Albanian adults, 2007 and 2009

\begin{tabular}{|c|c|c|c|c|c|c|c|c|c|c|}
\hline \multirow[b]{2}{*}{$\begin{array}{l}\text { Age and } \\
\text { gender }\end{array}$} & \multicolumn{5}{|l|}{2007} & \multicolumn{5}{|l|}{2009} \\
\hline & $\begin{array}{l}\text { Daily } \\
\text { smokers }\end{array}$ & $\begin{array}{l}\text { Occasional } \\
\text { smokers }\end{array}$ & $\begin{array}{l}\text { Former } \\
\text { smokers }\end{array}$ & $\begin{array}{l}\text { Ever } \\
\text { smokers }\end{array}$ & $\begin{array}{l}\text { Quit } \\
\text { ratio }\end{array}$ & $\begin{array}{l}\text { Daily } \\
\text { smokers }\end{array}$ & $\begin{array}{l}\text { Occasional } \\
\text { smokers }\end{array}$ & $\begin{array}{l}\text { Former } \\
\text { smokers }\end{array}$ & $\begin{array}{l}\text { Ever } \\
\text { smokers }\end{array}$ & $\begin{array}{l}\text { Quit } \\
\text { ratio }\end{array}$ \\
\hline Total & 34.9 & 6.5 & 6.8 & 48.2 & 14.1 & 38.7 & $8.4^{*}$ & 7.5 & $54.6^{*}$ & 13.7 \\
\hline $18-19$ years & 14.2 & 9.0 & 0.5 & 23.7 & 2.1 & $25.0^{*}$ & $13.5^{*}$ & $3.3^{*}$ & $41.8^{*}$ & $7.9^{*}$ \\
\hline $20-24$ years & 29.1 & 11.1 & 2.5 & 42.7 & 5.9 & 35.5 & 10.8 & $4.3^{*}$ & $50.6^{*}$ & $8.5^{*}$ \\
\hline $25-34$ years & 35.4 & 7.5 & 2.9 & 45.8 & 6.3 & 38.7 & $9.4^{*}$ & $4.7^{*}$ & 52.8 & $8.9^{*}$ \\
\hline $35-44$ years & 36.0 & 5.3 & 6.7 & 48 & 14.0 & 38.9 & $8.3^{*}$ & 7.5 & 54.7 & 13.7 \\
\hline $45-54$ years & 37.6 & 6.2 & 9.0 & 52.8 & 17.0 & 39.0 & 6.0 & 8.8 & 53.8 & 16.4 \\
\hline $55-64$ years & 38.6 & 4.0 & 10.4 & 53 & 19.6 & 42.4 & $5.2^{*}$ & 10.8 & 58.4 & 18.5 \\
\hline $\begin{array}{l}\text { Over } \\
65 \text { years }\end{array}$ & 39.8 & 4.0 & 14.6 & 58.4 & 25.0 & 44.3 & $8.6^{*}$ & 13.0 & 65.9 & $19.7^{*}$ \\
\hline Males & 58.8 & 5.6 & 10.7 & 75.1 & 14.2 & 60.7 & 4.9 & 11.9 & 77.5 & 15.4 \\
\hline $18-19$ years & 26.9 & 15.6 & 1.0 & 43.5 & 2.3 & $44.4^{*}$ & $10.7^{*}$ & $4.3^{*}$ & $59.4^{*}$ & $7.2^{*}$ \\
\hline $20-24$ years & 49.3 & 9.8 & 3.0 & 62.1 & 4.8 & $58.4^{*}$ & $7.2^{*}$ & $5.5^{*}$ & $71.1^{*}$ & $7.7^{*}$ \\
\hline $25-34$ years & 64.2 & 6.7 & 5.3 & 76.2 & 7.0 & 65.4 & $5.2^{*}$ & $6.7^{*}$ & 77.3 & 8.7 \\
\hline $35-44$ years & 61.6 & 3.1 & 11.3 & 76 & 14.9 & 64.1 & $5.6^{*}$ & 11.3 & 81.0 & 14.0 \\
\hline $45-54$ years & 63.9 & 4.5 & 14.6 & 83 & 17.6 & 60.8 & $2.9^{*}$ & 14.3 & 78.0 & 18.3 \\
\hline $55-64$ years & 59.6 & 4.1 & 17.1 & 80.8 & 21.2 & 57.8 & $2.7^{*}$ & 17.9 & 78.4 & 22.8 \\
\hline $\begin{array}{l}\text { Over } \\
65 \text { years }\end{array}$ & 60.2 & 2.5 & 19.8 & 82.5 & 24.0 & 58.4 & 3.0 & 23.0 & 84.4 & 27.3 \\
\hline Females & 11.5 & 7.4 & 2.9 & 21.8 & 13.3 & $17.4^{*}$ & $11.9 *$ & 3.3 & $32.6^{*}$ & 10.1 \\
\hline $18-19$ years & 2.5 & 2.9 & 0.0 & 5.4 & 0.0 & $7.1^{*}$ & $16.1^{*}$ & $2.4^{*}$ & $25.6^{*}$ & $9.4^{*}$ \\
\hline $20-24$ years & 10.3 & 12.3 & 1.9 & 24.5 & 7.8 & $14.1^{*}$ & 14.2 & $3.2^{*}$ & $31.5^{*}$ & $10.2^{*}$ \\
\hline $25-34$ years & 8.9 & 8.3 & 0.8 & 18 & 4.4 & $14.3^{*}$ & $13.3^{*}$ & $2.8^{*}$ & $30.4^{*}$ & $9.2^{*}$ \\
\hline $35-44$ years & 10.2 & 7.5 & 2.0 & 19.7 & 10.2 & $13.3^{*}$ & $11.0^{*}$ & $3.7^{*}$ & $28.0^{*}$ & 13.2 \\
\hline $45-54$ years & 9.5 & 8.0 & 3.1 & 20.6 & 15.0 & $15.8^{*}$ & 9.3 & 2.9 & 28.0 & $10.4^{*}$ \\
\hline $55-64$ years & 16.4 & 3.9 & 3.3 & 23.6 & 14.0 & $26.1^{*}$ & $7.9^{*}$ & 3.4 & $37.4^{*}$ & $9.1^{*}$ \\
\hline $\begin{array}{l}\text { Over } \\
65 \text { years }\end{array}$ & 21.8 & 5.4 & 10.1 & 37.3 & 27.1 & $32.0^{*}$ & $13.5^{*}$ & $4.2^{*}$ & $49.7^{*}$ & $8.5^{*}$ \\
\hline
\end{tabular}

Sample size was 4000 . All estimates are weighted. Quit ratio is defined as the ratio of former smokers to ever smokers.

*Difference in 2009 from the year 2007 is statistically significant at the $95 \%$ confidence level.

purchased in the last year were illicit. Half of these respondents cited a missing tax stamp and/or a missing Albanian health warning and/or not having nicotine/tar information in Albanian as features of an illicit cigarette pack. Another 29\% cited tax stamps and health warnings written in a foreign language, and $27 \%$ cited the taste of the cigarettes.

Meanwhile, a cigarette pack with a tax stamp and health warning in Albanian was recorded for $93 \%$ of the most recent cigarette purchases. The share of cigarettes with a tax stamp and health warning in Albanian was independent of whether the information was self-reported or came from interviewer's inspection of a cigarette pack. Excluding cigarettes purchased in duty-free shops and abroad, cigarettes purchased from street vendors had the highest percentage of missing tax stamps and/ or health warnings in Albanian (16\%). The majority (70\%) of the most recent cigarette purchases occurred in convenience stores, while only a small percentage of recent cigarette transactions (8.5\%) involved street vendors.

\section{DISCUSSION}

Despite the implementation of new tobacco control policies in May 2007, the survey results indicate that smoking prevalence among Albanian males did not decrease, and that smoking rates among females in general and males aged 18-29 years continue to grow. The results did provide some indications that adopting stricter tobacco control laws in 2007 was a positive step. Self-reported exposure to cigarette advertising and exposure to second-hand smoke in all public spaces have both declined. The data also indicate some reduction in smoking intensity, a small increase in quit attempts, and an increase in quit ratios among 18-24 years olds.

In evaluating tobacco control policies, a limitation of this study is the lack of data to sufficiently gauge what trends in smoking rates might have been in the absence of recent policies. Trends in former communist Russia ${ }^{9}$ indicate that Albanian smoking rates, especially among females, may have increased more in the absence of the policies. Spurred by tobacco industry marketing and distribution practices, the failure to reduce smoking prevalence in Albania may be due to the social acceptability of smoking among males, ${ }^{10}$ growing female economic independence, increasing social acceptability of female smoking ${ }^{5} 11$ and the ongoing appeal of western products in Albania. ${ }^{11}$ The higher rates of female smoking among urban than rural dwellers is indicative of the above factors' influence.

The impact of the 2007 tobacco control policies on smoking prevalence should also be understood in the context of their inadequate enforcement and the increasing affordability of

Table 5 The percentage of daily smokers who during the past 12 months stopped using tobacco for $24 \mathrm{~h}$ or longer because were trying to quit

\begin{tabular}{|c|c|c|c|c|c|c|}
\hline \multirow[b]{2}{*}{ Age } & 2007 & 2009 & 2007 & 2009 & 2007 & 2009 \\
\hline & \multicolumn{2}{|l|}{ Total } & \multicolumn{2}{|l|}{ Male } & \multicolumn{2}{|c|}{ Female } \\
\hline All & 26.6 & 30.3 & 26.6 & 29.1 & 26.2 & $34.6^{*}$ \\
\hline $18-19$ years & 41.8 & $28.8^{*}$ & 45.9 & $21.3^{*}$ & 0.0 & $72.4^{*}$ \\
\hline $20-24$ years & 26.3 & 32.7 & 28.5 & 33.3 & 16.7 & $30.4^{*}$ \\
\hline $25-34$ years & 22.5 & $33.3^{*}$ & 23.1 & $31.6^{*}$ & 18.8 & $40.3^{*}$ \\
\hline $35-44$ years & 24.6 & 28.8 & 24.2 & 26.8 & 26.9 & $38.7^{*}$ \\
\hline $45-54$ years & 28.2 & 28.0 & 28.6 & 27.1 & 25.4 & 31.6 \\
\hline $55-64$ years & 23.1 & 28.9 & 21.6 & $29.2^{*}$ & 28.8 & 28.1 \\
\hline Over 65 years & 35.4 & 30.5 & 35.4 & 30.1 & 35.5 & 31.3 \\
\hline
\end{tabular}

Sample size was 4000 . All estimates are weighted.

*Difference in 2009 from the year 2007 is statistically significant at the $95 \%$ confidence level. 
cigarettes in Albania. The 2009 survey revealed that exposure to second-hand smoke is still extremely high, particularly in private workplaces, restaurants and bars. In addition, more than half the population reported exposure to some form of cigarette advertising. The high smoking rates found among younger smokers suggest that smoking prevalence may increase in the future in the absence of stronger tobacco control policies.

The quit rate in Albania remains low compared to countries with advanced tobacco control. Among adults, only $13.7 \%$ of ever smokers were former smokers in 2009, while in the United States, for example, $51.8 \%$ of the ever smokers in 2008 were former smokers. ${ }^{12}$ The introduction of cessation services, which are not currently available in Albania, could help increase the number of former smokers, especially among females, whose quit rates remain low despite increasing quit attempts. In addition, quit rates might be increased through better enforcement of advertising bans and smoke-free laws, as well as increasing the tax on cigarettes.

Emerging literature on tax policy points to the importance of taking inflation and income growth into account. ${ }^{13}$ While real cigarette prices increased by $3.4 \%$ between the two surveys, real GDP increased by $12 \%$ in the same period. ${ }^{14}$ In addition, the official unemployment rate declined from $13.7 \%$ (first quarter of 2007 ) to $12.7 \%$ (last quarter of 2008). Economic growth and lower unemployment increase purchasing power and thereby the affordability of cigarettes. The July 2009 tobacco tax increase from 40 Lek to 50 Lek per pack is a step in the right direction. If the tax is fully passed on to consumers, cigarette prices will increase, on average, by $7.3 \%$.

Opponents of higher cigarette taxes argue that higher tobacco taxes will lead to illicit cigarette trade. Historically, the share of illicit cigarettes on the market in Albania has been high, as it has been in other Balkan states such as Bosnia-Herzegovina or Macedonia. ${ }^{4}$ This share, however, does not seem to be related to tobacco taxes/prices. Illicit cigarettes occupied about $72 \%$ of the total market in 2001 when a pack of cigarettes cost about US $\$ 0.30{ }^{3}$ but in 2007 , when a pack of cigarettes cost approximately US\$1.30 (AATS-1), WHO estimated that $40-50 \%$ of cigarettes consumed in Albania were illicit. ${ }^{4}$ In addition, the higher average price paid for illicit cigarettes suggests that attributes other than the price could play a role in their market penetration. Anecdotal evidence from the survey participants revealed that illicit cigarettes were perceived as being of higher quality, similar to the situation in Vietnam. ${ }^{15}$

Our 2009 estimate of cigarette consumption based on the survey is $21.2 \%$ higher than taxed consumption based on the official statistical records on production, imports and exports. ${ }^{2}$ This would suggest that the illicit cigarettes occupied a little over $20 \%$ of the market in 2009, again a decline since 2007. Our estimate is likely to be conservative since our survey does not capture cigarettes consumed by youth and there may be underreporting of cigarette use. However, the Albanian Customs Directorate also believes that illicit cigarette trade in Albania is on the decline as the quantity of cigarettes clearing customs has been substantially increasing in recent years. Between the first 7 months of 2007 and the first 7 months of 2009 the total number of cigarettes that cleared customs increased by $22.5 \%{ }^{2}$ Since $95 \%$ of legally consumed cigarettes are imported (conversation between Vice Minister of Finance Mima Florion and E Zaloshnja, Tirana, August 2009), the total consumption would need to increase by $21.4 \%$ to absorb this increase in cigarette imports. Even though consumption of cigarettes increased during this period, our surveys indicate that total consumption increased by only 8\% between April 2007 and April 2009.

\section{What this paper adds}

This study provides the first assessment of the impact of the May 2007 Tobacco Control Law in Albania.

- This study demonstrates that adopting stricter tobacco control laws, but inadequately enforcing them, does not curb smoking prevalence.

Therefore, some of the legal imports must have substituted for illegal cigarettes during a period when the average nominal price of a cigarette pack increased from US\$1.30 to US\$1.40.

The inspection of cigarette packs revealed that about $7 \%$ were suspected of being illegal due to missing tax stamps/health warnings in Albanian. However, 23\% of all smokers believed that some of the cigarettes that they had purchased in the last year were illicit. The discrepancy between the micro-level estimates based on our survey and the macro-level estimate using trade and consumption data may be due to under-reporting of illicit cigarette purchases by smokers. The seasonality of illicit cigarette flows and higher smoking intensity among those consuming illicit cigarettes may also contribute to this discrepancy.

A limitation of this study is the failure to inspect cigarette packs in the first wave of the survey, since that would have allowed us to assess the trend in illicit cigarette consumption based on micro-level data. In addition, attrition in the sample required replacement of some of those originally interviewed in the 2007 sample.

To lower smoking prevalence and improve public health, the government of Albania should enforce existing tobacco control policies, and adopt further policies as recommended by the WHO's Framework Convention on Tobacco Control, which Albania ratified in April 2006. Experience from other countries indicates that a comprehensive set of tobacco control policies that are simultaneously implemented can achieve large reductions in smoking prevalence. ${ }^{16-20}$

Acknowledgements The authors would like to thank Silva Bala from the Lung Disease Hospital in Tirana, Albania for reviewing the study plan and the results of the data collection, and Elizabeth Ward and Evan Blecher from the American Cancer Society for their valuable comments on the manuscript.

Funding The American Cancer Society provided funding for this study.

\section{Competing interests None.}

Ethics approval This study was conducted with the approval of The National Committee of Ethics, Ministry of Health of Albania.

Contributors Dr Zaloshnja supervised data collection and performed data analysis. He drafted the Data and methods and Results sections of the paper. Drs Ross and Levy drafted the survey instrument and the Introduction and Discussion sections.

Provenance and peer review Not commissioned; externally peer reviewed.

\section{REFERENCES}

1. Muço M. Economic transition in Albania: political constraints and mentality barriers. http://www.nato.int/acad/fellow/95-97/muco.pdf

2. Albanian Customs Directorate. Customs statistics. 2009. http://www.dogana gov.al/doc/BULETINI-FISKALJanar-Korrik2009.htm?PHPSESSID =8566480df7 a6bba9e4cc 78a1c 194c5b0 (accessed 15 Oct 2009)

3. Tobacco Reporter. Winter bonus issue. Tobacco Reporter 2001

4. World Health Organization. The European tobacco control report 2007 Copenhagen: Regional Office for Europe, 2007.

5. Ross H, Zaloshnja E, Levi D, et al. Results from the Albanian Adult Tobacco Survey. Cent Eur J Public Health 2008;16:182-8.

6. The American Association for Public Opinion Research. Standard Definitions final dispositions of case codes and outcome rates for surveys. Deerfield, Illinois: AAPOR, 2009. 
7. Levy P, Lemeshow S. Sampling of populations: methods and applications. New York: John Wiley, 1999.

8. See News. SEE Marcroeconomic Indicators - CPI. 2009. http://www.seenews.com/ news/latestnews/seemacroeconomicindicators-cpi-updatedmay19 2009-155109/ (accessed 7 Sep 2009).

9. Zaridze D. Patterns of smoking in Russia. In: Boyle P, Gray N, Henningfield J, et al, eds. Tobacco: science, policy and public health. New York: Oxford University Press, 2004.

10. Lokshin M, Beegle K. Forgone earnings from smoking: evidence for a developing country. Geneva: World Bank,2006.

11. Shapo L, Gilmore AB, Coker R, et al. Prevalence and determinants of smoking in Tirana city, Albania: a population-based survey. Public Health 2003; 117:228-36.

12. Centers for Disease Control and Prevention (CDC). Number of smokers and number of smokers who have quit. 2009. http://www.cdc.gov/tobacco/ quit_smoking/how_to_quit/you_can_quit/alone/ (accessed 7 Sep 2009).

13. Blecher EH, van Walbeek CP. Cigarette affordability trends: an update and some methodological comments. Tob Control 2009;18:167-75.
14. Central Intelligence Agency. Albania. The World Factbook. 2009. https://www. cia.gov/library/publications/the-world-factbook/geos/al.html (accessed 7 Sep 2009).

15. Joossens L. Vietnam: smuggling adds value. Tob Control 2003;12:119-20.

16. Office on Smoking and Prevention. Reducing tobacco use: a report of the Surgeon General. Atlanta, GA: Centers for Disease Control and Prevention, National Center for Chronic Disease Prevention and Health Promotion, Department of Health and Human Services, 2000

17. Levy DT, Hyland A, Higbee $C$, et al. The role of public policies in reducing smoking prevalence in California: results from the California tobacco policy simulation model. Health Policy 2007;82:167-85.

18. Levy DT, Benjakul S, Ross $\mathrm{H}$, et al. The role of tobacco control policies in reducing smoking and deaths in a middle income nation: results from the Thailand SimSmoke simulation model. Tob Control 2008;17:53-9.

19. Levy DT, Ross H, Zaloshnja E. The Albania SimSmoke tobacco policy simulation model. Cent Eur J Public Health 2008:16:189-98.

20. Levy DT, Cho S, Kim YM, et al. An evaluation of the impact of tobacco control policies in Korea using the SimSmoke model: the unknown success story. Am J Public Health Published Online First 13 May 2010. 